NASA/TM-2003-212115

\title{
Simulation Model Development for Icing Effects Flight Training
}

Billy P. Barnhart, Edward G. Dickes, and David R. Gingras

Bihrle Applied Research, Inc., Jericho, New York

Thomas P. Ratvasky

Glenn Research Center, Cleveland, Ohio 
Since its founding, NASA has been dedicated to the advancement of aeronautics and space science. The NASA Scientific and Technical Information (STI) Program Office plays a key part in helping NASA maintain this important role.

The NASA STI Program Office is operated by Langley Research Center, the Lead Center for NASA's scientific and technical information. The NASA STI Program Office provides access to the NASA STI Database, the largest collection of aeronautical and space science STI in the world. The Program Office is also NASA's institutional mechanism for disseminating the results of its research and development activities. These results are published by NASA in the NASA STI Report Series, which includes the following report types:

- $\quad$ TECHNICAL PUBLICATION. Reports of completed research or a major significant phase of research that present the results of NASA programs and include extensive data or theoretical analysis. Includes compilations of significant scientific and technical data and information deemed to be of continuing reference value. NASA's counterpart of peerreviewed formal professional papers but has less stringent limitations on manuscript length and extent of graphic presentations.

- TECHNICAL MEMORANDUM. Scientific and technical findings that are preliminary or of specialized interest, e.g., quick release reports, working papers, and bibliographies that contain minimal annotation. Does not contain extensive analysis.

- CONTRACTOR REPORT. Scientific and technical findings by NASA-sponsored contractors and grantees.
- CONFERENCE PUBLICATION. Collected papers from scientific and technical conferences, symposia, seminars, or other meetings sponsored or cosponsored by NASA.

- SPECIAL PUBLICATION. Scientific, technical, or historical information from NASA programs, projects, and missions, often concerned with subjects having substantial public interest.

- TECHNICAL TRANSLATION. Englishlanguage translations of foreign scientific and technical material pertinent to NASA's mission.

Specialized services that complement the STI Program Office's diverse offerings include creating custom thesauri, building customized databases, organizing and publishing research results ... even providing videos.

For more information about the NASA STI Program Office, see the following:

- Access the NASA STI Program Home Page at http://www.sti.nasa.gov

- E-mail your question via the Internet to help@sti.nasa.gov

- Fax your question to the NASA Access Help Desk at 301-621-0134

- Telephone the NASA Access Help Desk at 301-621-0390

- Write to:

NASA Access Help Desk

NASA Center for AeroSpace Information 7121 Standard Drive

Hanover, MD 21076 
NASA/TM-2003-212115

\section{Simulation Model Development for Icing Effects Flight Training}

Billy P. Barnhart, Edward G. Dickes, and David R. Gingras

Bihrle Applied Research, Inc., Jericho, New York

Thomas P. Ratvasky

Glenn Research Center, Cleveland, Ohio

Prepared for the

General Aviation Technology Conference and Exhibition 2002

sponsored by the Society of Automotive Engineers

Wichita, Kansas, April 16-18, 2002

National Aeronautics and

Space Administration

Glenn Research Center 
Trade names or manufacturers' names are used in this report for identification only. This usage does not constitute an official endorsement, either expressed or implied, by the National Aeronautics and Space Administration.

Available from

NASA Center for Aerospace Information 7121 Standard Drive

Hanover, MD 21076
National Technical Information Service 5285 Port Royal Road Springfield, VA 22100

Available electronically at http:/ /gltrs.grc.nasa.gov 


\title{
Simulation Model Development for Icing Effects Flight Training
}

\author{
Billy P. Barnhart, Edward G. Dickes, and David R. Gingras \\ Bihrle Applied Research, Inc. \\ Jericho, New York 11753 \\ Thomas P. Ratvasky \\ National Aeronautics and Space Administration \\ Glenn Research Center \\ Cleveland, Ohio 44135
}

\begin{abstract}
A high-fidelity simulation model for icing effects flight training was developed from wind tunnel data for the DeHavilland DHC-6 Twin Otter aircraft. First, a flight model of the un-iced airplane was developed and then modifications were generated to model the icing conditions. The models were validated against data records from the NASA Twin Otter Icing Research flight test program with only minimal refinements being required. The goals of this program were to demonstrate the effectiveness of such a simulator for training pilots to recognize and recover from icing situations and to establish a process for modeling icing effects to be used for future training devices.
\end{abstract}

\section{INTRODUCTION}

In response to a 1997 White House Initiative to reduce aviation accidents, NASA formed the Aviation Safety Program (AvSP) in 1999. The seven-year program has been tasked to reduce aviation accident rates by $80 \%$ by 2007 and by $90 \%$ by 2017 . Accident and incident reports were analyzed to focus efforts on areas of highest return. These studies showed that $13 \%$ of all weather-related accidents were due to airframe icing.

To address the icing hazard, NASA has developed a number of tools to supplement pilot training. To date, these tools consist of educational \& training videos and computer-based training CD-ROMs. However, a task within the System Wide Accident Prevention Project of AvSP is currently underway to develop a flight simulator that incorporates icing effects for pilot training applications. The purpose of the Pilot Simulator Training for Aircraft Icing Effects (PSIM) activity is to provide pilots with ground-based training facilities that provide a realistic simulation of in-flight icing encounters. This capability will provide pilots a pre-exposure to the adverse effects of icing on airplane performance, stability and control. It will serve as a tool for initial and recurrent pilot training to provide awareness of the consequences of an icing encounter and the knowledge of how to best manage potential adverse maneuvers that may result from icing-induced loss of control.
In order to establish this icing effects flight training capability, NASA Glenn Research Center teamed with Bihrle Applied Research and the Wichita State University in 1998 to develop a flight simulation demonstrator. The work also establishes a methodology for developing flight simulators that incorporate icing effects that can be used by flight training organizations, operators, airframe manufacturers, and pilots in safety training programs.

A typical application for such a flight modeling process would be to add the capability to existing flight trainers. In such a case, a baseline flight model would already exist. This effort focuses on the steps needed to augment a baseline model with appropriate data to model the effects of icing. In the case of the Twin Otter, no appropriate baseline simulation was available; therefore, as an additional step, one was developed and validated as part of the effort. It was important to have both baseline and iced simulations from a pilot training standpoint, so that a pilot could be exposed to the juxtaposition of both conditions. Starting from the baseline simulation also allowed researchers to assess, in an incremental fashion, the level of modification and steps required to implement icing effects to an existing baseline. To accomplish this, the PSIM effort was designed to proceed in three phases, a baseline model development and validation (BASELINE), a horizontal tail icing model development and validation (ICE01), and a full aircraft icing model development, assessment, and validation (ICE02).

Once a baseline simulation structure was established, each phase of the flight model development focused primarily on the development of aerodynamics models and control system models. The basis for each of the developmental aerodynamics and control models was low speed wind tunnel data. These data were used to populate table driven models of aerodynamics forces, moments, and hinge moments. The models were then validated with flight data. To complete the validation, physics-driven modifications are made to the raw windtunnel data and then reintroduced to the simulation. The revised model is then reevaluated against an independent data set until appropriate acceptance criteria are met. In this effort, modifications applied to the 
wind-tunnel data were noted and applied to subsequent efforts (Figure 1). For example, modifications made to baseline data were applied to ICE01 data during the ICE01 development process. Modifications made during the ICE01 validation would then be applied during ICE02 model development etc. This approach allowed researchers to evaluate procedural modifications and their applicability to the development of a flight model encompassing icing effects with out a priori knowledge of their effects on the airplane flying qualities and performance.

The aircraft chosen for the simulation development programs was the DeHavilland DHC-6 Twin Otter (Figure 2), a twin engine, high wing configuration. The Twin Otter is a key asset in the Icing Research program at the NASA Glenn Research Center (Figure 3). The NASA Glenn Team has extensive operational experience with this aircraft in icing conditions and with the airplane modified with artificial ice shapes, and has supplied all flight data used during the simulation development effort described herein (References 1 and 2).

The remainder of this paper provides background information pertaining to the structure and development of the baseline and the ICE01 and ICE02 flight models as well as their validation. The paper also presents a number of the modifications made to the raw wind-tunnel data as a result of the validation process.

\section{FLIGHT MODEL DEVELOPMENT PROCESS}

The development of a simulator involves modeling external physical contributions that act on the air vehicle to compute a new vehicle state and presenting observations of those states to the pilot via visual, tactile, aural, or vestibular means. The flight model, as discussed herein, is the component of the simulation that implements the physics of flight and provides state observations to the rest of the simulator. Typical subcomponents of the flight model are equations of motion, propulsion model, ground reaction, aerodynamics model, and flight control model.

In the development of the baseline Twin Otter simulation these sub-components were assembled and implemented in a commercial off the shelf simulation environment, D-Six ${ }^{\circledR}, \quad$ (Reference 3). The following sections provide a discussion of each component.

\section{EQUATIONS OF MOTION AND INTEGRATION}

A standard thirteen-state, quaternion-based, Newtonian representation of the six-degree of freedom airplane equations of motion formed the basis of the flight model. Aircraft position, velocity, and rotational states were integrated from accelerations computed from force and moment contributions provided by aerodynamics, propulsion, and ground interaction models.

\section{GROUND REACTION}

The ground reaction model provides forces and moments to the equations of motion (EOM) that represent landing gear functionality and its interaction with the ground. The Twin Otter's tricycle landing gear was modeled as three spring and damper assemblies located at each wheel contact point. The model accounted for nose wheel steering and representative gear deflection. Since landing gear fidelity was not the focus of this effort, this simple representation was sufficient to allow for take off and landing and appropriate representation of the aircraft attitude on take off.

\section{PROPULSION MODEL}

The twin-engine propulsion system of the Twin Otter was modeled using thrust coefficients that were determined for the 3-bladed $8.5-\mathrm{ft}$ propeller from the Hartzell propeller chart. These values were truncated within the aircraft power coefficient and advance ratio ranges and modeled in tabular form. The power coefficient was computed from independent (left and right) torque pressure commands, propeller rotational speeds, and density ratios. Each power coefficient was then used to compute appropriate thrust values to be applied along the engine thrust lines. Using thrust line locations and orientations, thrust data were converted to body axis forces and moment and supplied to the six-DOF EOM.

\section{AERODYNAMIC MODEL}

The main effort of the flight model development was to establish a successful methodology for modeling the aerodynamic effects of icing conditions. The general approach was to use a combination of experimental data from wind tunnels and flight test data to derive the aerodynamic flight characteristics.

The baseline aerodynamics model was developed using both wind-tunnel data and flight-extracted parameters. The following sections provide details pertaining to data from each source.

\section{Wind Tunnel Data}

Wind tunnel tests were conducted using a $6.5 \%$-scale model of the Twin Otter (Figure 4). A number of tests were conducted in the Wichita State University's (WSU) 7'x10' low-speed wind tunnel in Wichita, Kansas to identify appropriate static characteristics. Additional wind tunnel tests were then conducted using the same model at the Bihrle Applied Research's Large Amplitude Multiple Purpose (LAMP) Facility in Neuburg a.d. Donau, Germany, where the dynamic damping characteristics of the aircraft were obtained. This facility contains a multiple purpose rotary-balance rig that is capable of obtaining dynamic data, both rotational and forced oscillation data, as well as static data, over a large range 
of angles of attack and sideslip angles. Rotary-balance (wind-axis damping) and forced-oscillation (body-axis damping) tests were conducted using this rig. A significant amount of additional static data was also collected. During each test forces and moments acting on the wind tunnel model were measured with a sixcomponent balance. Data reduction and conversion yielded aerodynamic coefficients in a wind tunnel axes system.

The WSU wind tunnel data range extended from $-12^{\circ}$ to $+20^{\circ}$ angle of attack for $0^{\circ}, 10^{\circ}$, and $20^{\circ}$ sideslip angles at $0^{\circ}$ flaps. Data were collected at only $0^{\circ}$ sideslip angle for $20^{\circ}$ and $40^{\circ}$ flap settings. The Bihrle LAMP test provided an extensive set of static data at each flap deflection for further refinement of the model. These data were used to extend the angle of attack range from $-20^{\circ}$ to $+40^{\circ}$ and, because of the observed nonlinear variations in the aerodynamic characteristics beyond $20^{\circ}$ of sideslip, were also used to extend the sideslip functionality to $\pm 30^{\circ}$ for all six body-axis force and moment coefficients.

The wind tunnel data were analyzed to determine the model structural dependencies and to insure the preservation of all nonlinear effects. The initial definition of the basic airframe was built from the most significant functional dependencies, which for this aircraft were angle of attack, angle of sideslip and flap deflection. Increments were determined for control deflections, dynamic damping, and power effects.

A merging of the two data sets was accomplished for the evaluation and determination of control effectiveness modeling. For the WSU wind tunnel data set, runs were conducted on the basic Twin Otter with primarily full (-26 and $+14^{\circ}$ ) and half elevator deflections. Rudder effectiveness was measured at full deflections. Since a comprehensive set of control surface deflections had been tested at the Bihrle LAMP facility, these data (for the elevator and rudder, as well as for the ailerons) were used to define the nonlinear variation in control authority as a function of surface deflections and combined with the WSU control effectiveness data result in a comprehensive control effectiveness model (Figure 5). Elevator and aileron effectiveness exhibited flap dependencies, and these characteristics were incorporated as well.

The Bihrle LAMP rotary-balance (wind axis) and forcedoscillation (body axis) data were used to define the Twin Otter aircraft's dynamic damping characteristics for coordinated and uncoordinated motions, respectively. These data were mechanized separately and combined in the simulation using the techniques proposed by Kalviste (Reference 4) where the implementation of the data is governed by the actual model test motions. For the wind-axis damping terms, traditionally referred to as rotary balance data, nonlinear variations in the forces and moments due to rotation rate, sideslip angle and flap deflection were mechanized in the model (For example, see Figure 6). The body-axis dynamic damping terms, deduced from the forced oscillation tests, were mechanized as incremental coefficients that were a function of the non-dimensionalized body rate, and not as derivatives with respect to rate as was classically done in the past. This method of handling the body axis damping terms permits the proper modeling of the nonlinearities that are commonly found in the stall and post-stall angle of attack regions (Figure 7). As shown in Figure 7, these damping characteristics were also found to be a function of flap deflection.

An example of the longitudinal component of the aerodynamics model structure is shown in the build up of the pitching moment. The pitching moment coefficient modeling reflects its functional dependencies on angle of attack, sideslip, flap deflection, elevator deflection, rotation rate and pitch rate. The total coefficient is produced as a sum of several terms that are each tabular data with the shown dependencies. The first table, $\mathrm{C}_{\mathrm{m}_{\mathrm{BASI}}}$, represents the static pitching moment coefficient for the basic clean configuration as a function of angle of attack, sideslip angle and flap deflection. The incremental coefficient due to elevator deflection for the clean configuration, $\Delta \mathrm{C}_{\mathrm{m}_{\mathrm{DE}}}$, is modeled as an additional table with the functional dependencies shown. The aircraft's dynamic damping characteristics are represented in the next two sets of tables. The incremental pitching moment coefficient due to rotation about the velocity vector is modeled by the table $\Delta \mathrm{C}_{\mathrm{m}_{\text {ROT }}}$. The rotational effect due to sideslip for the longitudinal coefficients is symmetrical, such that the increment for a positive sideslip and rotation rate is the same as that for the same magnitude negative sideslip and rotation rate, and has been mechanized accordingly by the functional dependency on the product of the rotation rate multiplied by the sign of the sideslip angle and the absolute value of the sideslip angle. The body-axis pitch rate damping, $\Delta \mathrm{C}_{\mathrm{m}_{\mathrm{Q}}}$, as mentioned before, is mechanized as an incremental table that is a function of pitch rate, as well as angle of attack and flap deflection.

$$
\begin{aligned}
& \mathrm{C}_{\mathrm{m}_{\text {TOTAL CLEAN }}}=\mathrm{C}_{\mathrm{m}_{\text {BAsIC }}}(\alpha, \beta, \delta \mathrm{f}) \\
& +\Delta \mathrm{C}_{\mathrm{m}_{\mathrm{DE}}}(\alpha, \delta \mathrm{e}, \delta \mathrm{f}) \\
& +\Delta \mathrm{C}_{\mathrm{m}_{\mathrm{ROT}}}(\alpha, \Omega \mathrm{b} / 2 \mathrm{~V} * \operatorname{SGN}(\beta),|\beta|, \delta \mathrm{f}) \\
& +\Delta \mathrm{C}_{\mathrm{m}_{\mathrm{Q}}}(\alpha, \mathrm{q} \overline{\mathrm{c}} / 2 \mathrm{~V}, \delta \mathrm{f})
\end{aligned}
$$

Similarly, lateral-directional characteristics were modeled as a nonlinear multidimensional build up. An example of this is the rolling moment coefficient implementation. 


$$
\begin{aligned}
\mathrm{C}_{\mathrm{I}_{\text {TOtAl CleAN }}} & =\mathrm{C}_{\mathrm{I}_{\mathrm{BAsI}}}(\alpha, \beta, \delta \mathrm{f}) \\
& +\left[\Delta \mathrm{C}_{\mathrm{I}_{\mathrm{DA}}}(\alpha,|\delta \mathrm{a}|, \delta \mathrm{f})\right]^{*} \operatorname{SGN}(\delta \mathrm{a}) \\
& +\left[\Delta \mathrm{C}_{\mathrm{I}_{\mathrm{DR}}}(\alpha,|\delta \mathrm{r}|)\right]^{*} \operatorname{SGN}(\delta \mathrm{r}) \\
& +\left[\Delta \mathrm{C}_{\mathrm{I}_{\mathrm{ROT}}}(\alpha, \Omega \mathrm{b} / 2 \mathrm{~V} * \operatorname{SGN}(\beta),|\beta|, \delta \mathrm{f})\right]^{*} \operatorname{SGN}(\beta) \\
& +\Delta \mathrm{C}_{\mathrm{I}_{\mathrm{p}}}(\alpha, \mathrm{pb} / 2 \mathrm{~V}, \delta \mathrm{f}) \\
& +\Delta \mathrm{C}_{\mathrm{I}_{\mathrm{R}}}(\alpha, \mathrm{rb} / 2 \mathrm{~V}, \delta \mathrm{f})
\end{aligned}
$$

The rolling moment coefficient is mechanized as a function of angle of attack, sideslip, flap deflection, aileron and rudder deflections, rotation rate, as well as both roll and yaw rates. The first table, $\mathrm{C}_{\mathrm{I}_{\mathrm{BASIC}}}$, represents the static rolling moment coefficient for the basic clean configuration as a function of angle of attack, sideslip angle and flap deflection, and therefore defines the basic nonlinear static lateral stability of the aircraft. The incremental effect due to aileron deflection is represented in the table $\Delta \mathrm{C}_{\mathrm{I}_{\mathrm{DA}}}$ as a function of angle of attack, the absolute value of the total aileron deflection, and flap deflection. The output from this table is multiplied by the sign of the total aileron deflection to account for rolling to the left or right. The table $\Delta \mathrm{C}_{\mathrm{IR}_{\mathrm{DR}}}$ represents the incremental rudder effectiveness as a function of angle of attack, and the absolute value of the rudder deflection. The output from this table is multiplied by the sign of the actual rudder deflection to account for yawing to the left or right. Rotational rolling moment characteristics, representing the wind-axis roll damping, are included in the table $\Delta \mathrm{C}_{\mathrm{I}_{\text {ROT }}}$ as a function of four independent variables; angle of attack, the product of the rotation rate and the sign of the sideslip angle, the absolute value of the sideslip angle, and flap deflection. As with all lateral-directional tables mechanized with a 'sign of sideslip' functionality, the result of the table lookup must be multiplied by the sign of the sideslip angle, due to the fact that the functional dependency on sideslip angle is anti-symmetric with the sign of sideslip, with positive sideslip angle and a rotation in one direction producing a variation similar, but opposite in sign, to negative sideslip rotating in the opposite direction. The body-axis damping terms for roll and yaw rate are represented by the tables $\Delta \mathrm{C}_{\mathrm{I}_{\mathrm{P}}}$ and $\Delta \mathrm{C}_{\mathrm{I}_{\mathrm{R}}}$ and are mechanized as functions of angle of attack, roll or yaw rate, and flap deflection.

\section{Modification to Baseline Wind-Tunnel Data}

Both the WSU and the LAMP wind tunnel data were measured at low dynamic pressures/Reynolds numbers. As would be expected for thick airfoils like that incorporated on the Twin Otter, it was noted that the stall angle of attack, and, hence, the maximum lift coefficient were under predicted with the raw wind tunnel data. To insure that the full-scale stall angle was properly identified, flight derived and "flight manual" data were used to determine where the full-scale airplane stall occurred.

The total lift coefficient of the flight test aircraft was measured for various flap deflections (Reference 2) and is shown in Figure 8. Maximum lift coefficient values were also calculated using the stall speed placard information provided in the aircraft as a function of weight and flap deflection. Using this information, adjustments were made to the wind tunnel lift coefficient data (Figure 9). The associated static and dynamic aerodynamic characteristics of all six coefficients at stall were also shifted to the revised stall angles of attack as a function of flap deflection. Experience has shown that the general trends in the dynamic data observed for the model at its stall angle of attack should be representative for the aircraft in its stall region. The Reynolds number effect is diminished as angle of attack increases beyond the region where the wing stall influences the dynamic characteristics, and typically there is no longer any effect by at most 40 degrees angle of attack.

\section{Flight Extracted Data}

Since no aerodynamics effects due to propulsion were measured during wind tunnel testing these effects were determined from flight data. The flight test data used to extract these effects were obtained from the NASA Iced Aircraft Stability and Control Program conducted in 1992 (Reference 1), the NASA/FAA Tail plane Icing Program (TIP) conducted in 1995 and 1997 (Reference 2) and the Pilot Simulator Training for Aircraft Icing Effects (PSIM) program conducted in 2001. The maneuver set used for the effort consisted of steady state trim points and throttle transitions.

Equation error parameter identification was used to extract the effects of propulsion on the longitudinal aerodynamics of the Twin Otter (Figure 10). Thrust dependent terms that were functions of angle of attack, flap deflection, and thrust coefficient were added to the baseline aerodynamics model. For each of these terms, table values, for given independent argument breakpoints, were identified from a concatenated set of data. These estimates were implemented into the new aerodynamics model, which was exercised with data measured in flight. During each iteration, the model predicted total aerodynamic coefficients were used with coefficients extracted from flight data to compute a residual vector. The root sum of squares of this residual vector was then minimized by a nonlinear least squares algorithm (Reference 5).

The approach described above relies on several assumptions: the propulsion model used for extraction 
from flight is of good fidelity and the baseline aerodynamics model is of good fidelity for thrust independent cases. Figure 11 contains an example of the results for the aerodynamic effect of propulsion on the pitching moment of the Twin Otter.

The resulting propulsion effects on the aerodynamics were modeled as functions of angle of attack, thrust coefficient and flap deflection and included as incremental tables for the appropriate coefficients, primarily pitching moment,

$\Delta \mathrm{C}_{\mathrm{m}_{\mathrm{CT}}}(\alpha, \mathrm{CT}, \delta \mathrm{f})$,

and axial force,

$\Delta \mathrm{C}_{\mathrm{A}_{\mathrm{CT}}}(\alpha, \mathrm{CT}, \delta f)$.

\section{CONTROL SYSTEM MODEL}

\section{$\underline{\text { Control Surface Gearing }}$}

Because the Twin Otter control system is reversible and comprised of mechanical linkages, the control system model was implemented using gains to convert yoke, wheel, and rudder positions to control surface positions. These control surfaces positions were then used to compute control surface effects in the aerodynamics model.

\section{Elevator Hinge Moment/Stick Force}

One observation from the icing flight test program was that the difference in elevator hinge moment was one of the strongest indicators of the reduced tail plane performance due to horizontal tail icing; with a progressive hinge moment lightening and reversal as the tail plane stall margin was reduced. Consequently, an effort was made to accurately model the elevator hinge moment characteristics in the PSIM simulator.

Hinge moment coefficient data from an Ohio State University wind tunnel test of a Twin Otter tail plane airfoil section (Reference 6) were used to generate a model of the forces on the elevator. These wind tunnel data were measured for the horizontal tail section alone without the presence of the wing. For modeling purposes, it was desired to generate tabular data as a function of wing angle of attack, so calculations of the downwash angle corrections (Reference 7) were made for each flap deflection to establish a relation between tail angle of attack and wing angle of attack. Hinge moments were then modeled as a function of angle of attack, and elevator and flap deflections. From the moments, stick forces were computed using a linkage model.

\section{BASELINE VALIDATION}

\section{Overdrive Equation Error Analysis}

A validation tool used in this analysis from the D-Six simulation environment, 'Overdrive', allows the validation of the simulation aerodynamic database against flightextracted data using the process illustrated in Figure 12. At each time slice, extraction of aerodynamic moment coefficients from the flight-recorded time history occurs as shown on the right side of Figure 12. Angular rates are numerically differentiated to obtain the angular acceleration of the vehicle. After the removal of the inertial effects, the remainder is nondimensionalized to calculate the aerodynamic force and moment coefficients experienced during flight. Also, at each time step, flightrecorded states, such as angle of attack, angle of sideslip, control surface positions, etc., are used to exercise the aerodynamic model in accordance with the aerodynamic model specification discussed previously. Each aerodynamic model element (i.e., pitching moment due to elevator, etc.) is stored and summed as prescribed in the aerodynamic model. By over-plotting the model predicted coefficients with the flight-extracted total coefficients, differences can be easily identified. Correlating the discrepancies with the excitation of the individual elements and parameters from the flight time history aids to isolate potential weaknesses in the aerodynamic model.

It should be emphasized that there is no integration during an Overdrive run. The states are completely restricted to the values from the time history. The advantage of this approach is that there is no propagation of error over time. Any differences between the model-predicted and the flight-extracted values are strictly the result of local error. This 'analog-matching' approach alleviates the problem associated with the propagation of error over time; any noise or dropout of signals would not affect the analysis of the subsequent events in the time history. Additionally, the flight control system is bypassed in this methodology thus avoiding any confusion between the error caused by aerodynamic modeling and the error from the flight control system model. Once the user is satisfied with the aerodynamic model, the entire simulation (including the aerodynamic model and flight control system modeling) can be validated by running the simulation in open-loop controlled by the flight-recorded control surface or pilot input.

The validation effort showed that, in general, the model correlated well with the flight records, however, some lateral-directional aerodynamic characteristics required scaling to improve the correlation. These included reducing the directional stability and the roll due to yaw 
rate term, and increasing the incremental roll due to rudder deflection. Examples of the overdrive comparisons of the final models for the baseline are shown in figures 13 and 14, for lateral-directional and longitudinal control doublets, respectively.

Using the overdrive technique, comparisons of predicted stick force were made against stick forces measured in flight. Figures 15 presents a sample set of plots of these comparisons. The model did not have the ability to trim out the initial forces, as was done in flight, so there is a constant bias between the two curves, but otherwise the correlation is very good as can be seen.

\section{ICE01 (TAIL PLANE ICE) SIMULATION DEVELOPMENT AND VALIDATION}

\section{AERODYNAMICS MODEL DEVELOPMENT}

\section{Wind Tunnel Data}

As part of the wind tunnel testing mentioned above, data were collected with ice shapes on the horizontal tail plane. As part of the Wichita State University tests, equivalent, simpler, ice shapes were evaluated that were demonstrated to produce essentially the same aerodynamic influences as the actual ice shapes during the sub-scale wind tunnel tests (Reference 8). These equivalent ice shapes were subsequently used during the remainder of the WSU tests and for the tests at the LAMP facility. To identify the effects of the horizontal tail ice accretion on the aerodynamic characteristics of the Twin Otter, these data were collected at test conditions identical to the baseline.

Ice accretions on the horizontal tail (ICE01) alter the basic aircraft's static pitching moment characteristics (Figure 16), particularly over the negative angle-of-attack region, as well as the control effectiveness of the elevator. To model these effects, the basic pitching moment table and the incremental pitching moment due to elevator deflection table are replaced by two new tables, $\mathrm{C}_{\mathrm{m}_{\mathrm{BASEI1}}}$ and $\Delta \mathrm{C}_{\mathrm{m}_{\mathrm{DEI1}}}$, that represent the airplane with ice accretions on the horizontal tail. These tables are functions of the same independent variables as the clean configuration.

$$
\begin{aligned}
& \mathrm{C}_{\mathrm{m}_{\text {TOTAL ICE } 1}}=\mathrm{C}_{\mathrm{m}_{\text {BASEI1 }}}(\alpha, \beta, \delta \mathrm{f}) \\
& +\Delta \mathrm{C}_{\mathrm{m}_{\mathrm{DEI1}}}(\alpha, \delta \mathrm{e}, \delta \mathrm{f}) \\
& +\Delta \mathrm{C}_{\mathrm{m}_{\mathrm{ROT}}}(\alpha, \Omega \mathrm{b} / 2 \mathrm{~V} * \operatorname{SGN}(\beta),|\beta|, \delta \mathrm{f}) \\
& +\Delta \mathrm{C}_{\mathrm{m}_{\mathrm{Q}}}(\alpha, \mathrm{q} \overline{\mathrm{c}} / 2 \mathrm{~V}, \delta \mathrm{f}) \\
& +\Delta \mathrm{C}_{\mathrm{m}_{\mathrm{CT}}}(\alpha, \mathrm{CT}, \delta \mathrm{f})
\end{aligned}
$$

The effect of ice buildup on the horizontal tail (ICE01) provided no more than a small influence on the basic lateral-directional aerodynamic stability characteristics, as expected. This effect is represented by the replacement table $\mathrm{C}_{\mathrm{I}_{\mathrm{BASEI}}}$ and is a function of angle of attack, sideslip angle, and flap deflection - the same independent variables as the clean configuration

\section{CONTROL SYSTEM MODEL}

The wind tunnel tests at Ohio State University included a unique set of data collected for a horizontal tail section with ice accretions on the leading edge. This data was utilized in exactly the same manner as was done for the baseline to generate a hinge moment model of the ICE01 configuration. The tabular data were a function of angle of attack and elevator and flap deflections, the same as the baseline model, and replaced the tables for the baseline model when it was desired to simulate the iced condition.

\section{VALIDATION}

The validation procedure discussed for the baseline model using the Overdrive process was also done for the ICE01 configuration. The data modifications that were incorporated into the baseline model, including the modifications to the stall angle of attack, the flight extracted propulsion aerodynamic effects, and those arising from the validation effort were all incorporated into the ICE01 model, as well. As a consequence, the validation showed very good agreement between the calculated and flight measured results immediately, which indicated that the effects of the ice accretion were well represented by the wind tunnel test data. The Overdrive plots for the ICE01 cases look very similar to the ones shown for the baseline model and, consequently, are not reproduced here.

\section{ICE02 (WING AND TAIL ICE) SIMULATION DEVELOPMENT AND EVALUATION}

\section{AERODYNAMICS MODEL DEVELOPMENT}

\section{Wind Tunnel Data}

As part of the wind tunnel testing mentioned above, data were also collected with equivalent ice shapes on the wing, vertical tail, and horizontal tail plane. As was done for the ICE01 testing, these data were collected at test conditions identical to those for the baseline.

This icing condition (ICE02) produces changes to all of the pitching moment terms (except the propulsion effect term which was initially assumed to be the same as that extracted from the baseline flight records), not just the basic static pitching moment characteristics and elevator effectiveness, as was seen for the horizontal tail ice 
alone. This is not surprising, since with ice accretions at the leading edges of both the wing and horizontal tail, it would be expected that the pitch characteristics would all be influenced. All of the replacement pitch tables are functions of the same independent variables as those for the clean configuration.

$$
\begin{aligned}
\mathrm{C}_{\mathrm{m}_{\text {TOTALICE02 }}} & =\mathrm{C}_{\mathrm{m}_{\mathrm{BASEI} 2}}(\alpha, \beta, \delta \mathrm{f}) \\
& +\Delta \mathrm{C}_{\mathrm{m}_{\mathrm{DEI} 2}}(\alpha, \delta \mathrm{e}, \delta \mathrm{f}) \\
& +\Delta \mathrm{C}_{\mathrm{m}_{\mathrm{ROT} / 2}}(\alpha, \Omega \mathrm{b} / 2 \mathrm{~V} * \mathrm{SGN}(\beta),|\beta|, \delta \mathrm{f}) \\
& +\Delta \mathrm{C}_{\mathrm{m}_{\mathrm{Q} 12}}(\alpha, \mathrm{q} \overline{\mathrm{c}} / 2 \mathrm{~V}, \delta \mathrm{f}) \\
& +\Delta \mathrm{C}_{\mathrm{m}_{\mathrm{CT}}}(\alpha, \mathrm{CT}, \delta \mathrm{f})
\end{aligned}
$$

Likewise, the ICE02 icing results in replacement tables for all of the terms in the rolling moment equation. Since there are ice accretions on both the wing and vertical tail, which together largely determine the roll characteristics, this is not a surprising result. All of the terms are functions of the same independent variables as the clean configuration tables.

$$
\begin{aligned}
\mathrm{C}_{\mathrm{I}_{\text {TOTALICEO2 }}} & =\mathrm{C}_{\mathrm{I}_{\mathrm{BASEI}}}(\alpha, \beta, \delta \mathrm{f}) \\
& +\left[\Delta \mathrm{C}_{\mathrm{I}_{\mathrm{DAI} 2}}(\alpha,|\delta \mathrm{a}|, \delta \mathrm{f})\right]^{*} \operatorname{SGN}(\delta \mathrm{a}) \\
& +\left[\Delta \mathrm{C}_{\mathrm{I}_{\mathrm{DRI} 2}}(\alpha,|\delta \mathrm{r}|)\right]^{*} \operatorname{SGN}(\delta \mathrm{r}) \\
& +\left[\Delta \mathrm{C}_{\mathrm{I}_{\mathrm{ROTI}}}(\alpha, \Omega \mathrm{b} / 2 \mathrm{~V} * \operatorname{SGN}(\beta),|\beta|, \delta \mathrm{f})\right]^{*} \operatorname{SGN}(\beta) \\
& +\Delta \mathrm{C}_{\mathrm{I}_{\mathrm{PI} 2}}(\alpha, \mathrm{pb} / 2 \mathrm{~V}, \delta \mathrm{f}) \\
& +\Delta \mathrm{C}_{\mathrm{I}_{\mathrm{RI} 2}}(\alpha, \mathrm{rb} / 2 \mathrm{~V}, \delta \mathrm{f})
\end{aligned}
$$

Wing stall occurred at a lower angle of attack for the ICE02 configuration because of the ice accretion on the wing leading edge. Indications are that it would also stall earlier for the full-scale aircraft, as well. It was reasoned that the presence of the ice on the wing leading edge for this configuration would likely separate the flow, thus promoting wing stall, in a similar manner for both the fullscale airplane and for the sub-scale wind tunnel model. As a consequence, no shift in the wing stall angle of attack was added to the ICE02 database as had been done for the other configurations.

With no pre-existing flight data for the ICE02 configuration from which to extract the equivalent propulsion related aerodynamic terms, the terms that were extracted for the baseline, un-iced model were assumed initially. As part of the validation effort the validity of this assumption will be determined.

\section{CONTROL SYSTEM MODEL}

The same elevator hinge moment modeling that was developed for the horizontal tail ice case was used for the ICE02 modeling since the ice shapes on the horizontal tail were the same in both.

\section{VALIDATION}

A validation effort, similar to that done for the baseline and ICE01 configurations is currently underway. Because there were no previous flight results for this condition, the validation for this case had to wait until new data from flights specifically flown for the PSIM effort were available (Reference 9). Early preliminary validation results show generally good correlation for this configuration, which is a promising indication that similar icing simulation models can be developed without a priori flight data. A sample Overdrive plot is shown in Figure 17. Except for some steady-state biases in the longitudinal data, which may be due to unmodeled power effects for this ice configuration, the correlation with the initial model is quite good.

\section{IMPLEMENTATION OF FLIGHT MODEL}

\section{DESKTOP REAL-TIME SIMULATION}

The simulation model was constructed in the form of data tables that were easily incorporated into the D-Six ${ }^{\circledR}$ realtime flight simulation software environment for the PC. This software includes all of the model independent code needed to run the simulation, including the equations of motion, graphics generation, etc. Consequently, realtime flight simulations of the Twin Otter can be performed on a desktop PC with just the addition of some type of flight control input devices. These can be as simple as game-type joysticks (but this option would lack the very important longitudinal force cue) or include a full complement of force-loaded controls. Out the window and Twin Otter instrument views are displayed on the computer screen or projection system (Figure 18). A full complement of analytical tools are included that provide, for example, plotting of any simulation parameter (Figure 19) and simulation playback.

\section{TRAINING COCKPIT LAB STATION}

The Twin Otter simulation flight model for icing effects flight training was interfaced with Bihrle's cockpit station and control loading system for further evaluation. The cockpit station is also driven with the D-Six ${ }^{\circledR}$ Simulation environment running on a state-of-the-art Pentium computer. The cockpit station includes out the window graphics, custom multi-channel instrument panel displays, control yoke column and rudder pedals, multilever throttle, and standard gear and flap levers (Figure 20). The control yoke was connected through an 
advanced Input/Output Device (IOD) interface to a Fokker loading device for simulation of longitudinal control forces, while the lateral control and rudder pedals were spring loaded. The hinge moment model was used to generate a model of the forces on the elevator and hence at the control yoke to supply the pilot with realistic control forces, including dynamic force characteristics. For the iced conditions, the control forces can become very large: a full tail stall was experienced during flight test with horizontal tail ice at full flap deflection and required 100-172 lbs of pull force for recovery.

The NASA test pilots that fly the Twin Otter were invited to perform checkout maneuvers with each of the icing conditions and have commented favorably on the training cockpit lab station. A more thorough evaluation is planned that will determine the minimum level of pilot cues that are necessary for the icing training task.

\section{CONCLUSION}

Once a baseline simulation flight model was established and validated, researchers successfully used wind-tunnel data to identify the effects of ice accretion on the aerodynamic characteristics of the vehicle and control feel. With these effects identified, specific portions of the flight model were targeted for augmentation to represent the new configuration. In the first case, where tail plane ice occurred, correlation between predicted aerodynamic coefficients and those extracted from flight was good. On occasion, biases were evident in comparisons and indicated deficiencies in the modeling of secondary effects of the propulsion system for example, or any thrust effects due to rapid angle of attack or sideslip changes. In addition, a model of the effect of icing on hinge-moments was developed from wind-tunnel data and evaluated. When implemented with the simulation and control loading hardware, the effects proved to be representative of the airplane.

The process of using wind-tunnel data to identify the effects of icing appears to have worked well in the case of the ICE02 configuration. In this case, wind tunnel data comparisons were used to identify longitudinal and lateral directional differences, and were used to modify the simulation. At the time of writing this paper, work on the ICE02 effort is still under way, but preliminary evaluations indicate that collecting wind-tunnel data to assess the effects of icing on the aerodynamics of a vehicle configuration without a priori knowledge is a success.

\section{REFERENCES}

1. Ratvasky, T.P., Ranaudo, R.J., Icing Effects on Aircraft Stability and Control Determined from Flight Data. Preliminary Results, NASA TM 105977, AIAA-93-0398, January 1993.
2. Ratvasky, T.P., Foss Van Zante, J. and Sim, A., NASA/FAA Tail plane Icing Program: Flight Test Report, NASA/TP-2000-209908, March 2000.

3. Bell, J.W., Application of a Multipurpose Simulation Design, AIAA Paper 97-3798, August 1997.

4. Kalviste, J: Use of Rotary Balance and Forced Oscillation Data in a Six Degrees of Freedom Simulation, AIAA Paper 82-1364, August 1982

5. Klein, V, "Identification Evaluation Methods," AGARD Lecture Series No. 104.

6. Gregorek, G.M., Dreese, J.J., and La Noe, K., Additional Testing of the DHC-6 Twin Otter Iced Airfoil Section at the Ohio State University 7'x10' Low Speed Wind Tunnel, NASA/CR-2000209921/Vol2, 2000.

7. Perkins, C.D., and Hage, R.E., Airplane Performance, Stability and Control, John Wiley and Sons, 1967.

8. Papadakis, M., Gile-Laflin, B.E., Youssef, G.M., Ratvasky, T.P., Aerodynamic Scaling Experiments with Simulated Ice Accretions, AIAA 2001-0833, January 2001.

9. Ratvasky, T.P., Blankenship, K., Rieke, W. and Brinker, D.J.: Iced Aircraft Flight Data for Flight Simulator Validation, SAE 2002-01-1528, NASA/TM2003-212114.

\section{CONTACT}

Bihrle Applied Research, Inc. (www.bihrle.com)

Billy P. Barnhart - Vice President, barbilly@optonline.net Edward G. Dickes - Senior Engineer, edickes@bihrle.com

David R. Gingras - Senior Engineer, dgingras@bihrle.com

\section{NASA Glenn Research Center}

Thomas P Ratvasky - Icing Branch, Thomas.P.Ratvasky@grc.nasa.gov

\section{DEFINITIONS, ACRONYMS, ABBREVIATIONS}

\section{Symbols}

The units for physical quantities used herein are presented in U.S. Customary Units. All aerodynamic data are referenced to the body axis system.

$\mathrm{b}$ : wing span, $\mathrm{ft}$

$\overline{\mathrm{c}}$ : mean aerodynamic chord, $\mathrm{ft}$

$\mathrm{C}_{\mathrm{A}}$ : axial-force coefficient, Axial force/ $\overline{\mathrm{q}} \mathrm{S}$

$\mathrm{C}_{\mathrm{N}}$ : normal-force coefficient, Normal force/ $\overline{\mathrm{q}} \mathrm{S}$

$\mathrm{C}_{\mathrm{Y}}$ : side-force coefficient, Side force/ $\overline{\mathrm{q}} \mathrm{S}$

$\mathrm{C}_{\text {; }}$ : rolling-moment coefficient, Rolling moment $/ \overline{\mathrm{q}} \mathrm{Sb}$

$\mathrm{C}_{\mathrm{m}}$ : pitching-moment coefficient, Pitching moment $/ \overline{\mathrm{q}} \mathrm{S} \overline{\mathrm{c}}$ 
$C_{n}$ : yawing-moment coefficient, Yawing moment $/ \overline{\mathrm{q}} \mathrm{Sb}$

$\mathrm{C}_{\mathrm{A}_{\mathrm{O}}}$ : axial-force coefficient due to pitch rate

$\mathrm{C}_{\mathrm{N}_{\mathrm{Q}}}$ : normal-force coefficient due to pitch rate

$\mathrm{C}_{Y_{P}}$ : side-force coefficient due to roll rate

$\mathrm{C}_{Y_{\mathrm{R}}}$ : side-force coefficient due to yaw rate

$\mathrm{C}_{I_{p}}$ : rolling-moment coefficient due to roll rate

$\mathrm{C}_{\mathrm{A}_{\mathrm{R}}}$ : rolling-moment coefficient due to yaw rate

$\mathrm{C}_{\mathrm{m}_{\mathrm{Q}}}$ : pitching-moment coefficient due to pitch rate

$\mathrm{C}_{\mathrm{n}_{\mathrm{p}}}$ : yawing-moment coefficient due to roll rate

$\mathrm{C}_{\mathrm{n}_{\mathrm{R}}}$ : yawing-moment coefficient due to yaw rate

$\mathrm{p}, \mathrm{q}, \mathrm{r}$ : body-axis roll, pitch, and yaw rates, $\mathrm{rad} / \mathrm{sec}$

$\overline{\mathrm{q}}$ : free-stream dynamic pressure, $\mathrm{lb} / \mathrm{ft}^{2}$

$\mathrm{S}$ : wing area, $\mathrm{ft}^{2}$

$\mathrm{V}$ : free-stream velocity, $\mathrm{ft} / \mathrm{sec}$

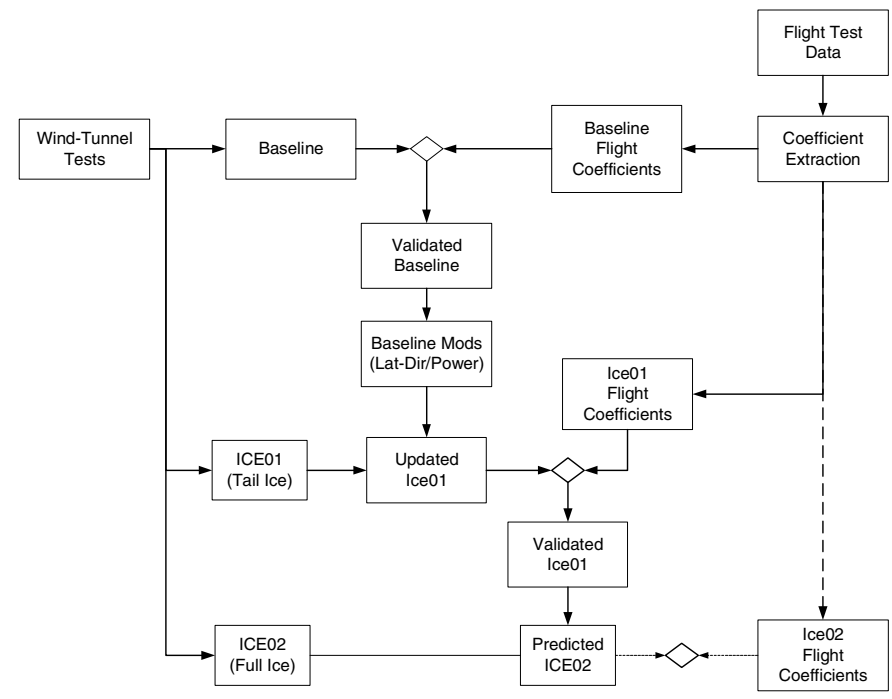

Figure 1. - Schematic of Development Process.

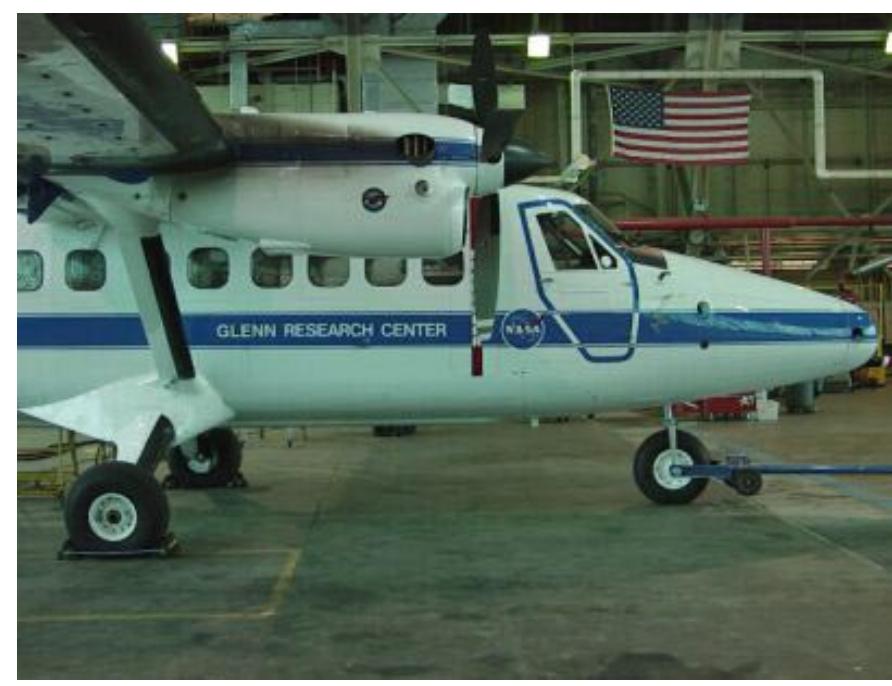

Figure 3. - NASA Glenn Research Center Icing Research Aircraft. $\alpha$ : angle of attack, deg

$\beta$ : angle of sideslip, deg

$\Delta$ : prefix for incremental component

$\Omega$ : rate of rotation about the velocity vector, $\mathrm{rad} / \mathrm{sec}$

$\Omega \mathrm{b} / 2 \mathrm{~V}$ : non-dimensional rotation rate, positive for clockwise spin

$\delta a$ : aileron deflection, positive when right trailing-edge is

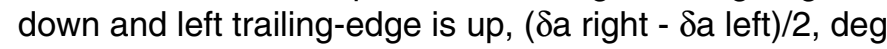
$\delta f:$ flap deflection, positive when trailing-edge is down,

\section{deg}

$\delta$ h: horizontal tail deflection, positive when trailing-edge is down, deg

$\delta$ : rudder deflection, positive when trailing-edge is left, deg

\section{Function}

SGN( ): sign function, returns 1 if the argument is positive or zero, -1 if it is negative
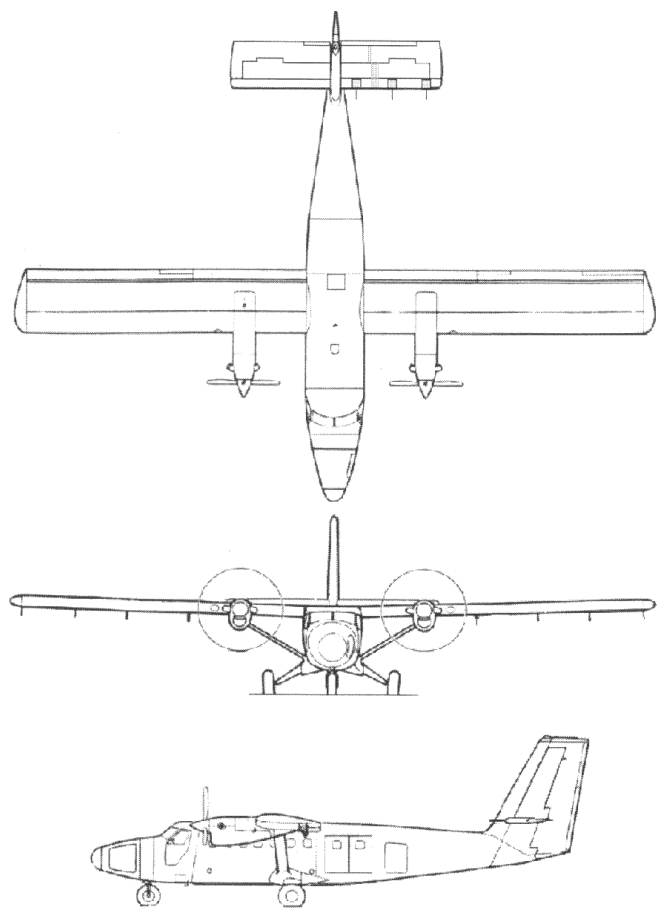

Figure 2. - DeHavilland DHC-6 Twin Otter Airplane.

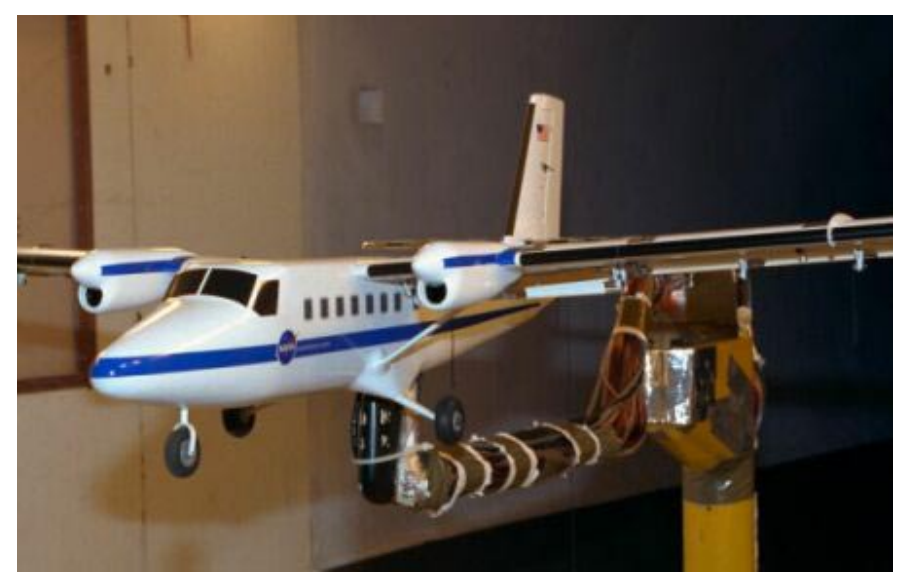

Figure 4. $-6.5 \%$-Scale Twin Otter wind tunnel model. 

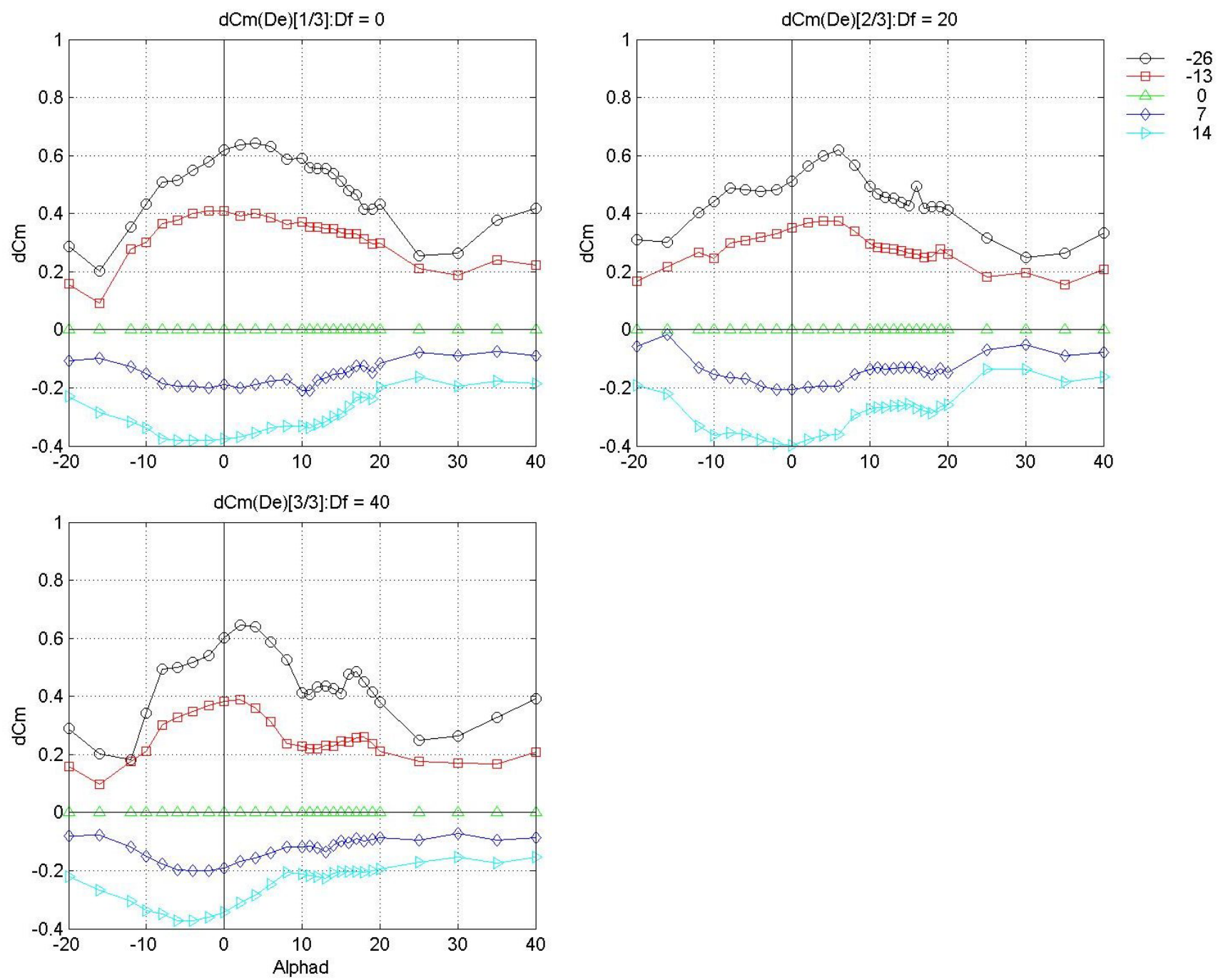

Figure 5. - Incremental pitching moment coefficient as a function of angle of attack, elevator and flap deflections.

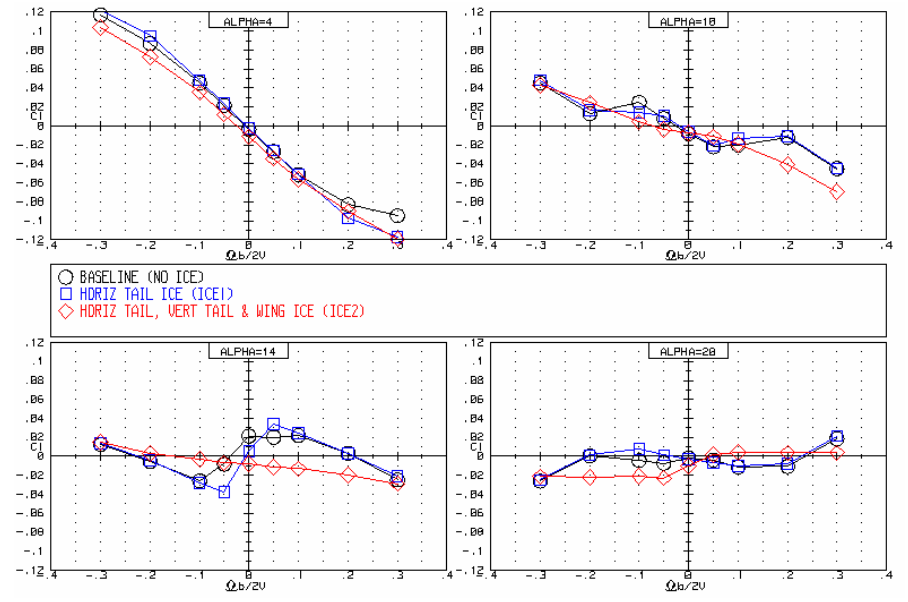

Figure 6. - Rotational rolling moment coefficient.

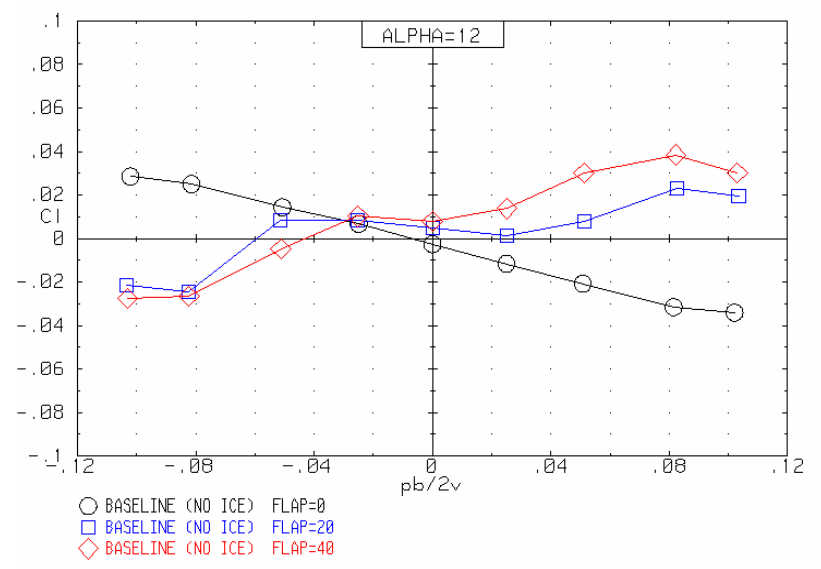

Figure 7. - Influence of Flap deflection on roll damping. 


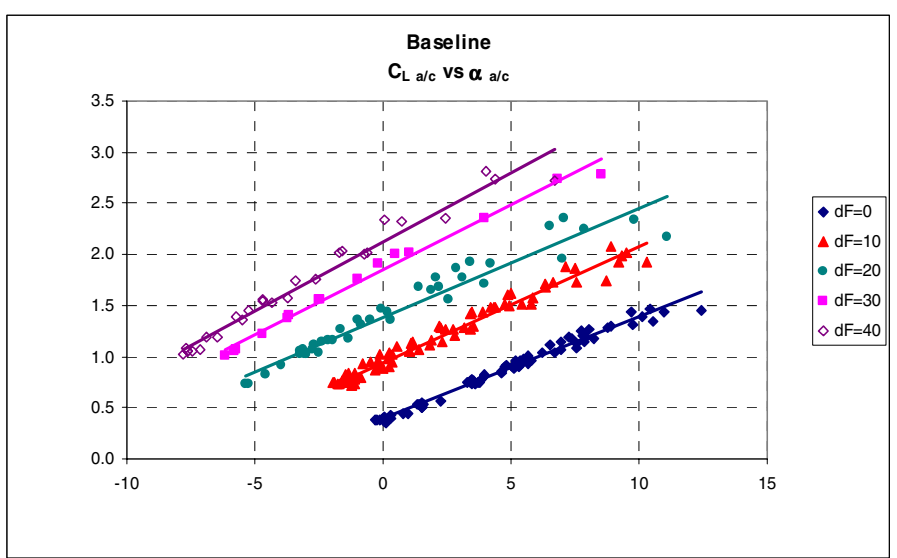

Figure 8. - Flight Test Total Lift Coefficient vs. Angle of Attack for Various Flap Deflections.(Reference: NASA/TP-2000-209908)

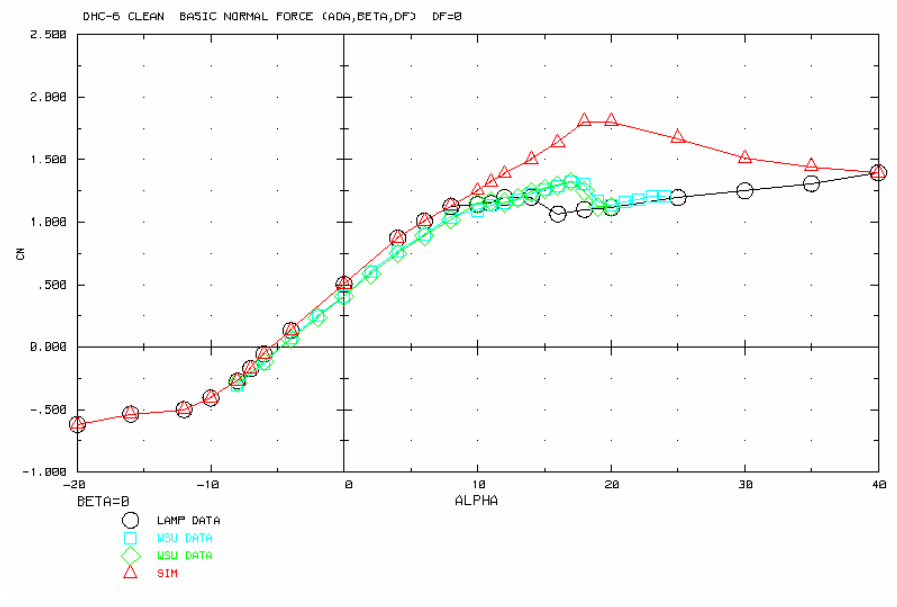

Figure 9. - Comparison of wind tunnel data and final simulation model Normal Force curve.

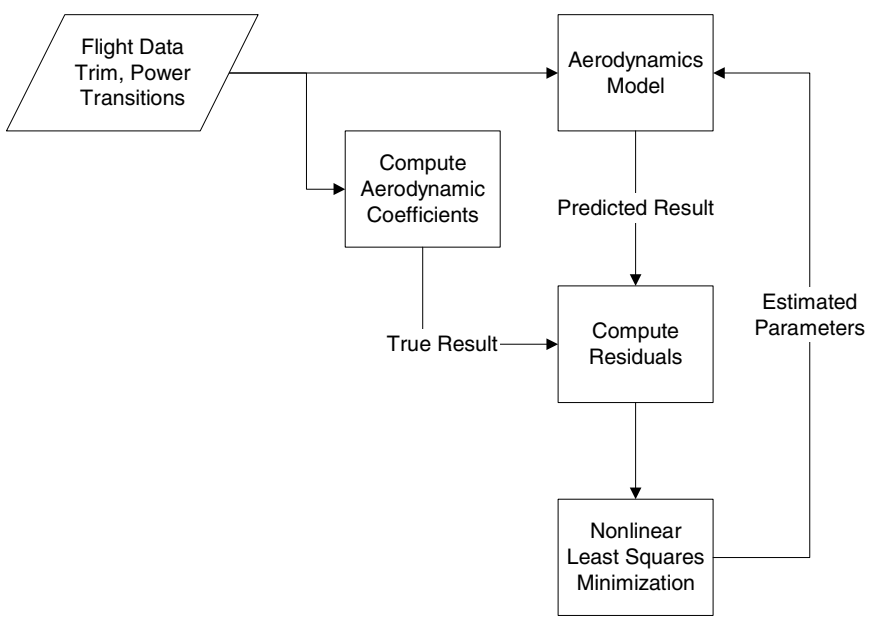

Figure 10. - Parameter Identification logic diagram.
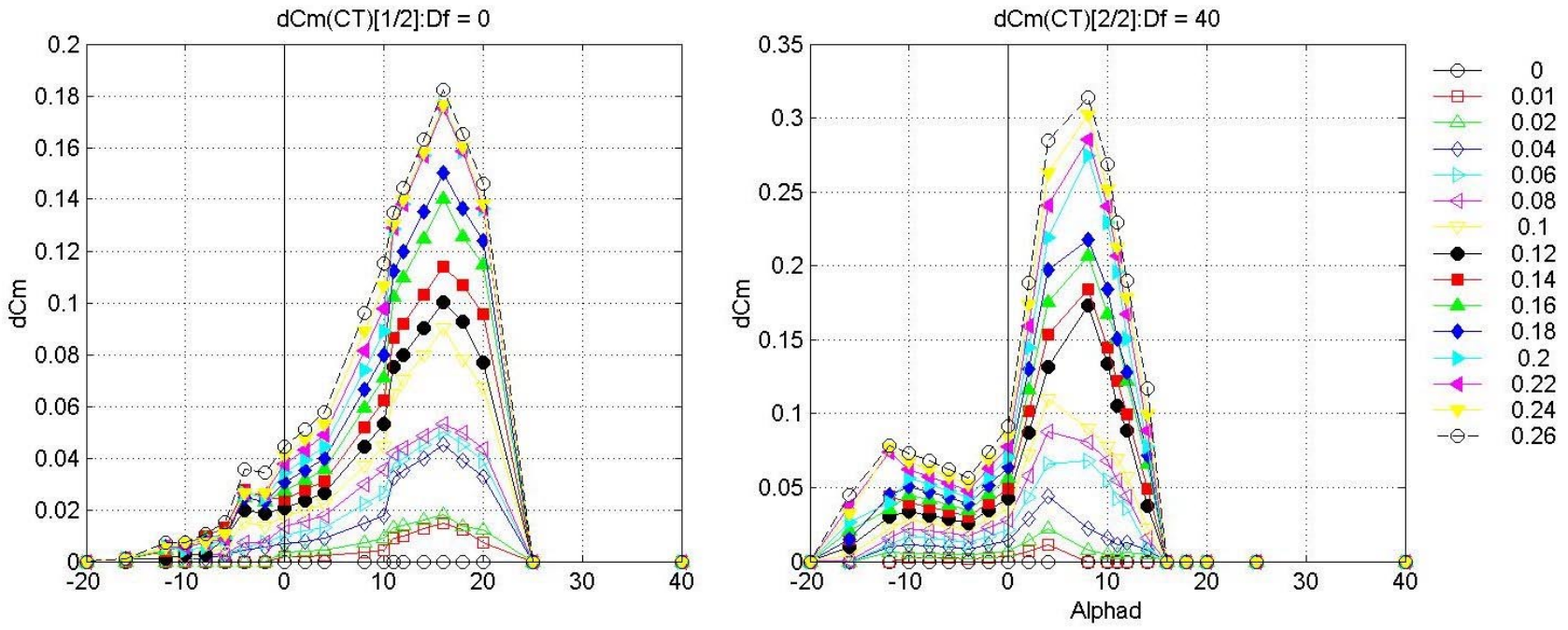

Figure 11. - Effect of propulsion $\left(C_{T}\right)$ on pitching moment coefficient. 
$\alpha, \beta$, Speed, Altitude,

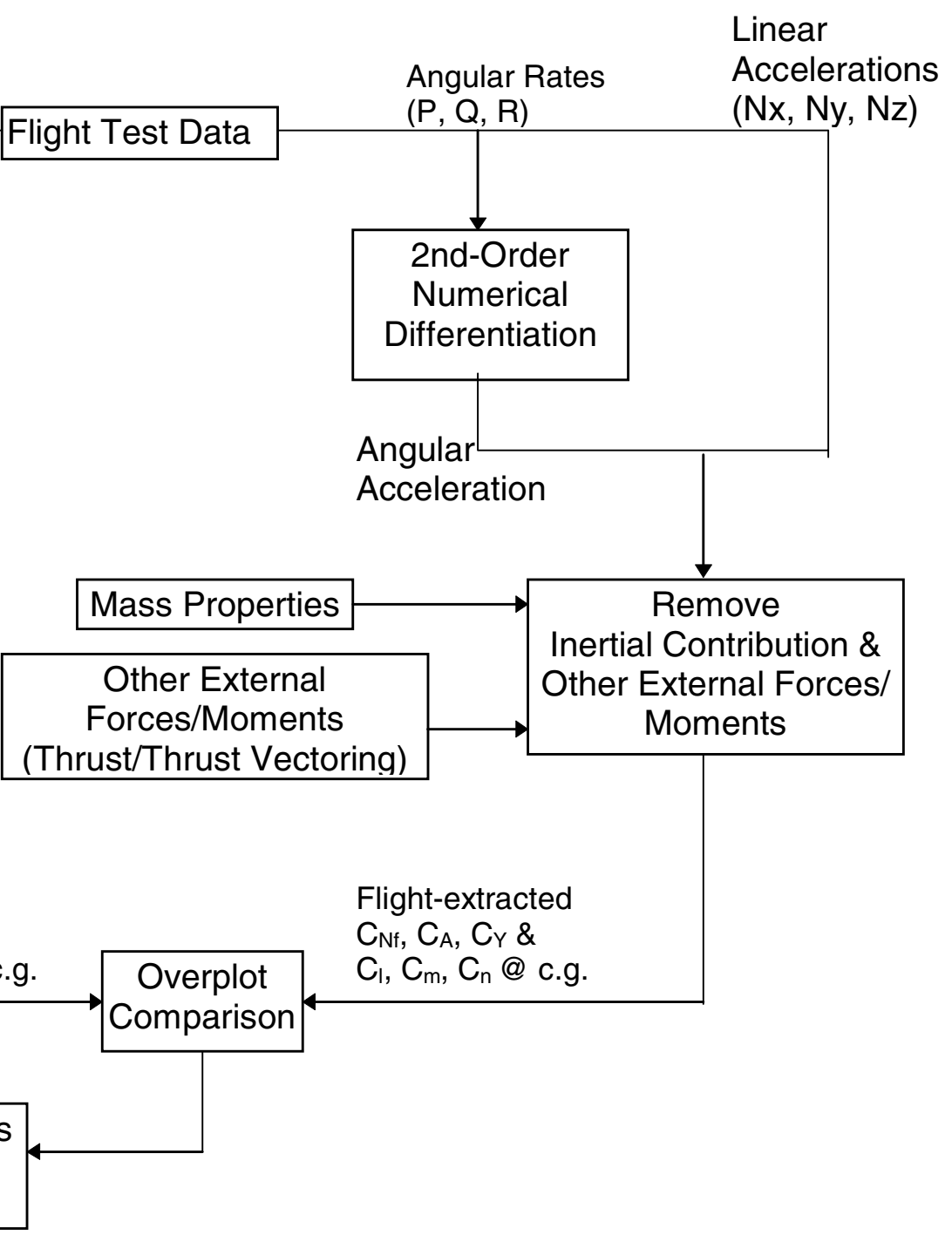

Figure 12. - OverDrive block diagram. 

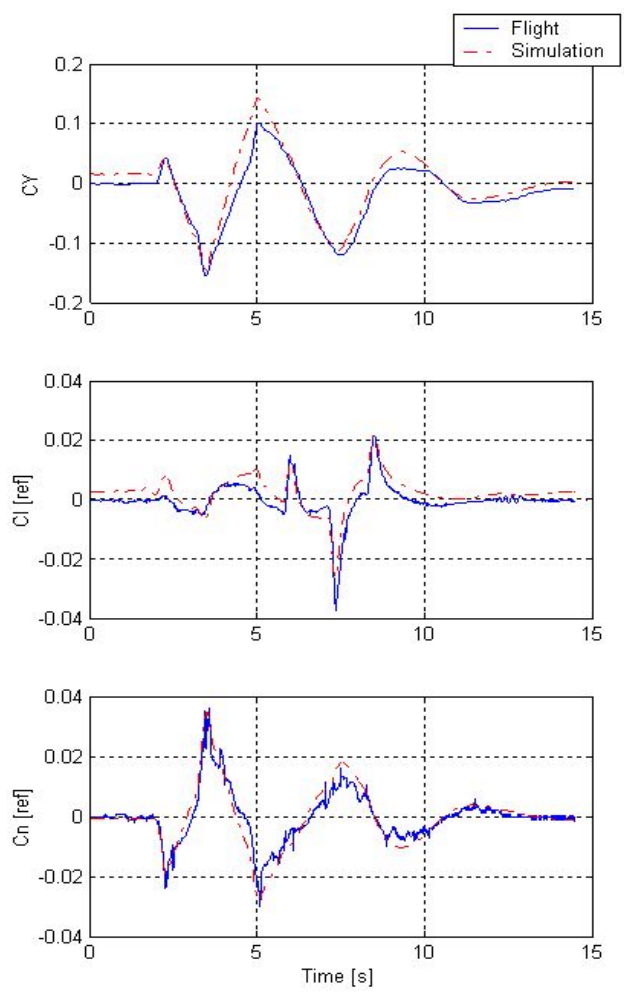

Figure 13. - Comparison of flight and simulation Overdrive results for final lateral-directional model.
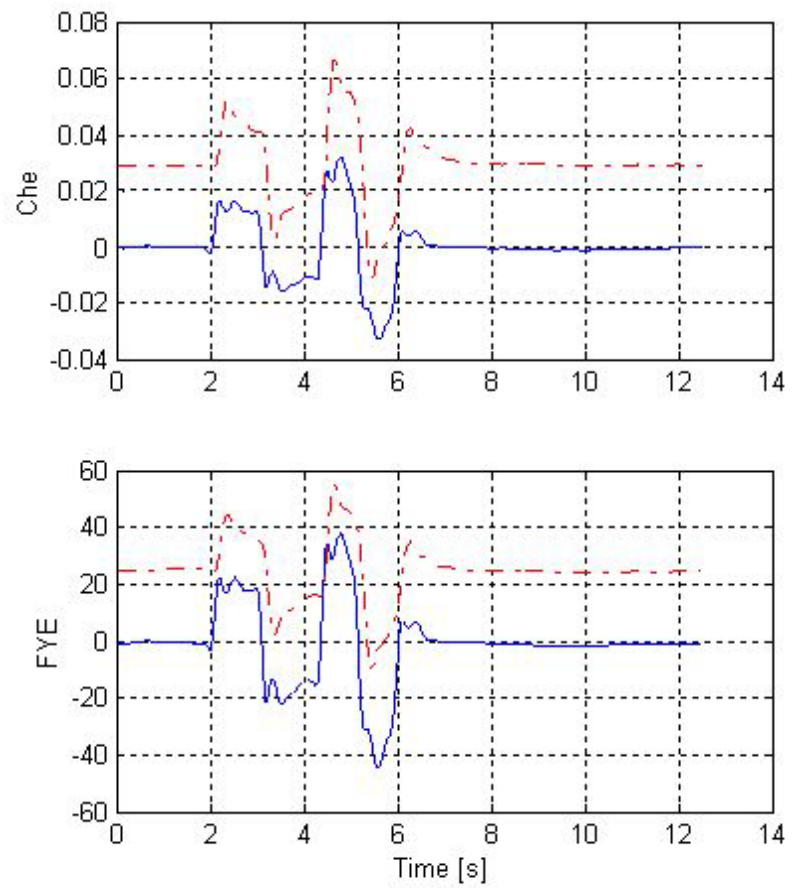

Figure 15. - Comparison of flight and simulation Overdrive for elevator hinge moment and stick forces elevator doublet; baseline model (no trim in sim).
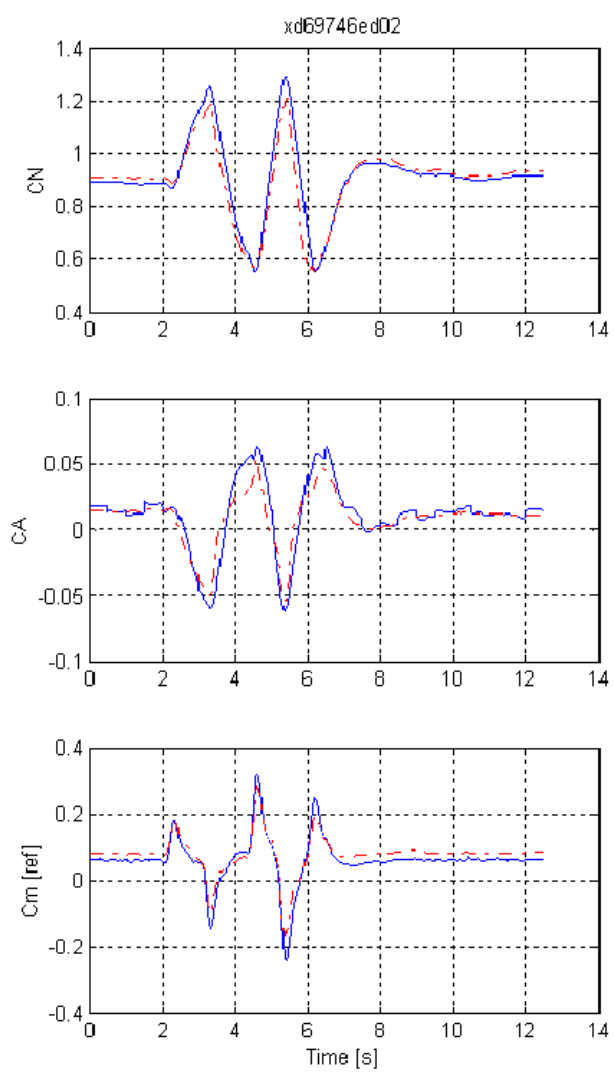

Figure 14. - Comparison of flight and simulation Overdrive results for final longitudinal model.

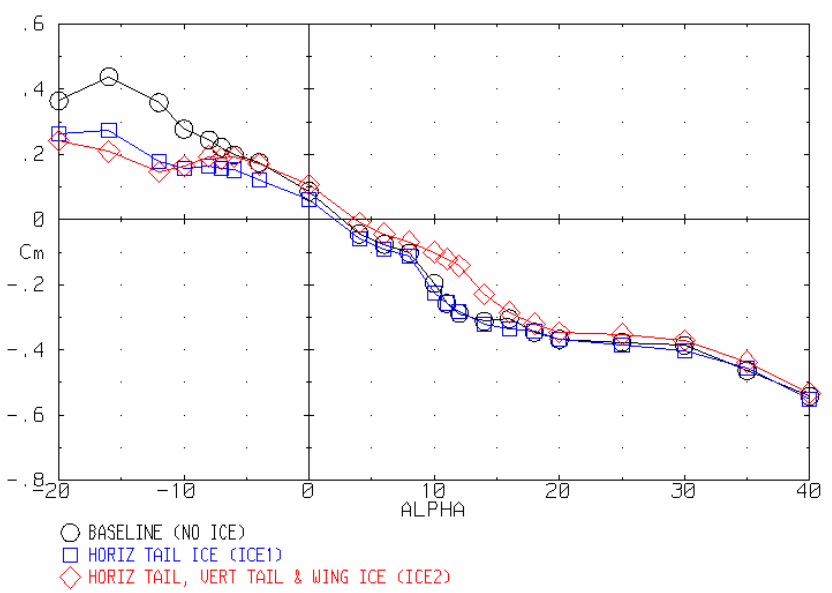

Figure 16. - Effect of ice accretion on static Pitching Moment Coefficient, flaps $=0$. 

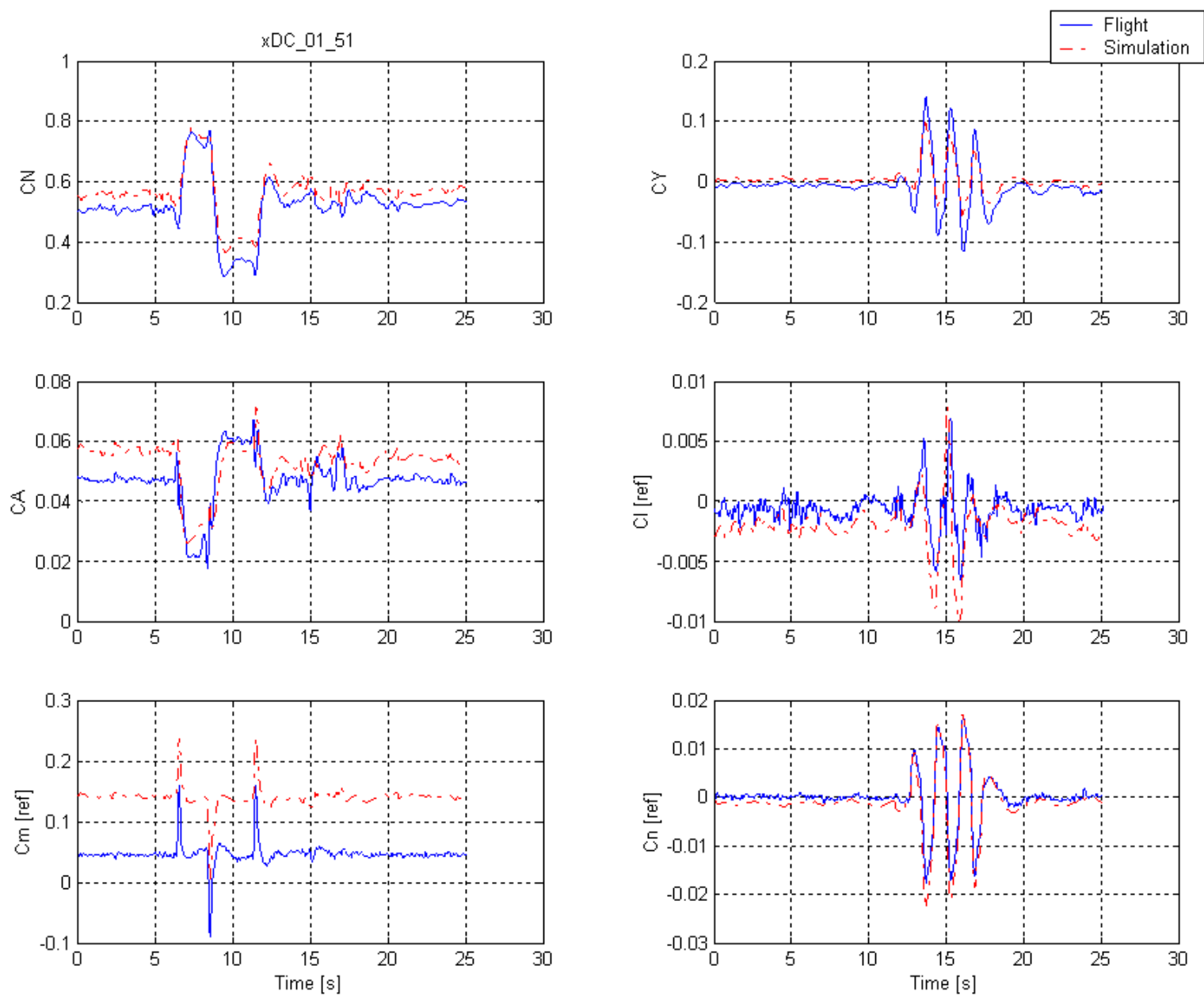

Figure 17. - Overdrive run with ICE02 showing degree of correlation of the initial model, prior to validation, with flight results. 

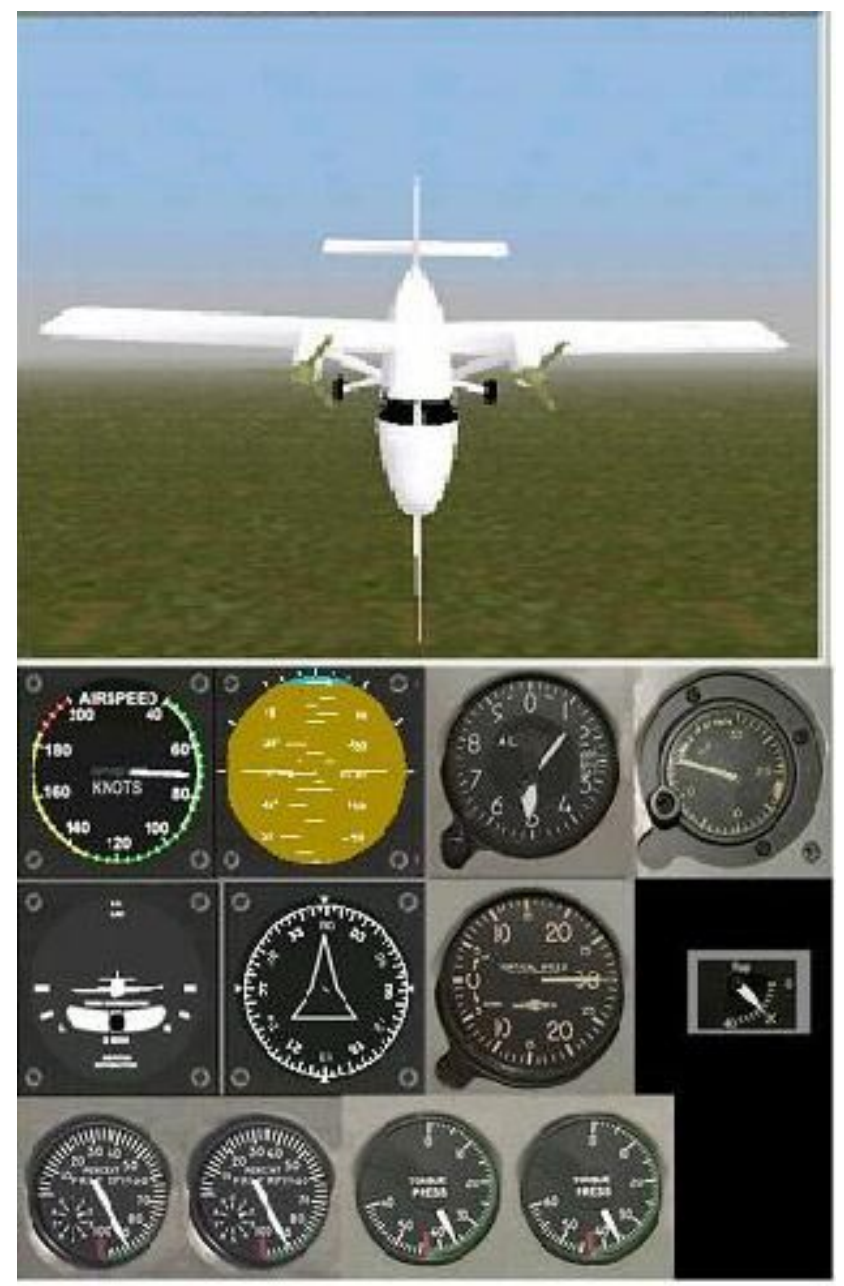

Figure 18. - Sample Desktop Sim Screens showing one aircraft external view and instrument panel.

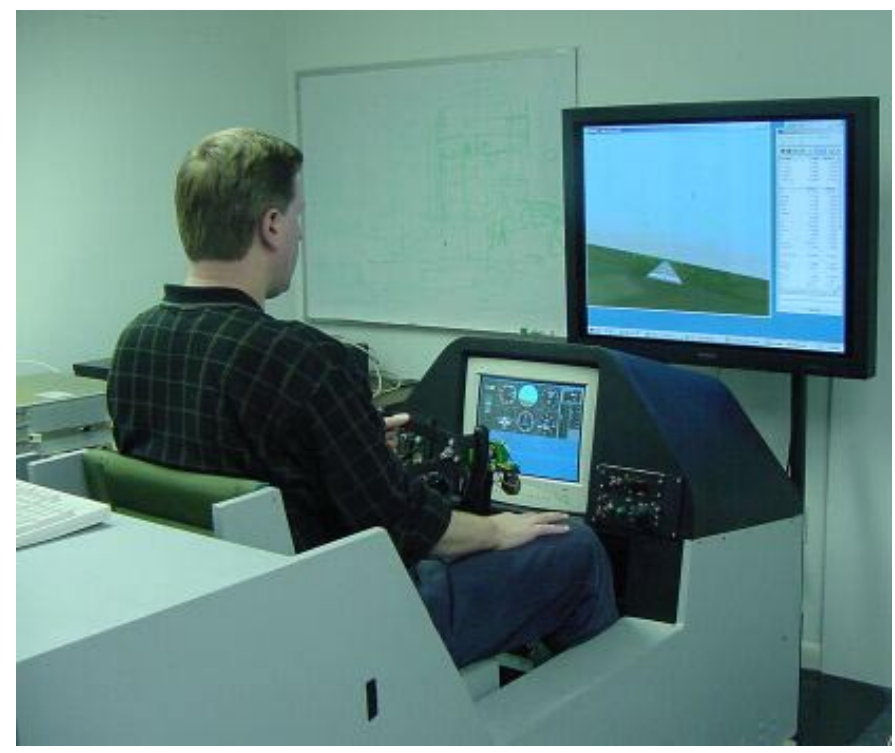

Figure 20. - BAR's Cockpit Station.

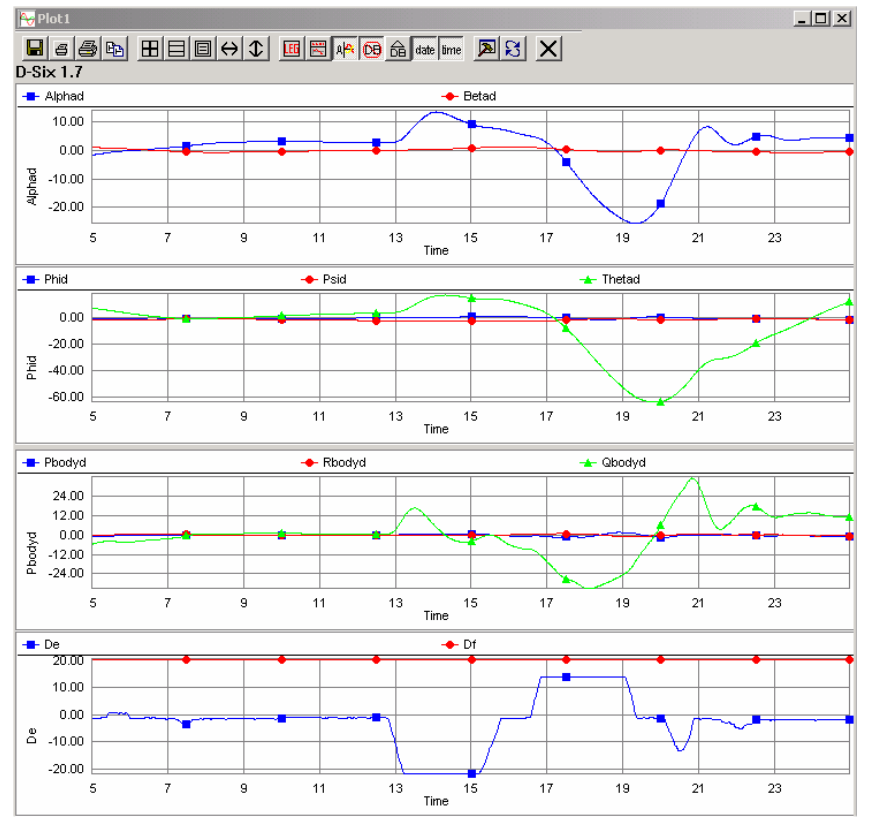

Figure 19. - An example of plotted variables available from the simulation. 


\begin{tabular}{|c|c|c|}
\hline \multicolumn{2}{|c|}{ REPORT DOCUMENTATION PAGE } & $\begin{array}{l}\text { Form Approved } \\
\text { OMB No. 0704-0188 }\end{array}$ \\
\hline \multicolumn{3}{|c|}{$\begin{array}{l}\text { Public reporting burden for this collection of information is estimated to average } 1 \text { hour per response, including the time for reviewing instructions, searching existing data sources, } \\
\text { gathering and maintaining the data needed, and completing and reviewing the collection of information. Send comments regarding this burden estimate or any other aspect of this } \\
\text { collection of information, including suggestions for reducing this burden, to Washington Headquarters Services, Directorate for Information Operations and Reports, } 1215 \text { Jefferson } \\
\text { Davis Highway, Suite 1204, Arlington, VA 22202-4302, and to the Office of Management and Budget, Paperwork Reduction Project (0704-0188), Washington, DC 20503. }\end{array}$} \\
\hline 1. AGENCY USE ONLY (Leave blank) & \begin{tabular}{|r|l} 
2. REPORT DATE & 3. \\
April 2003 &
\end{tabular} & $\begin{array}{l}\text { D DATES COVERED } \\
\text { echnical Memorandum }\end{array}$ \\
\hline \multicolumn{2}{|c|}{ Simulation Model Development for Icing Effects Flight Training } & 5. FUNDING NUMBERS \\
\hline \multicolumn{2}{|c|}{$\begin{array}{l}\text { 6. AUTHOR(S) } \\
\text { Billy P. Barnhart, Edward G. Dickes, David R. Gingras, and Thomas P. Ratvasky }\end{array}$} & WBS-22-728-20-01 \\
\hline $\begin{array}{l}\text { 9. SPONSORING/MONITORING AGE } \\
\text { National Aeronautics and } \mathrm{S}_{\mathrm{I}} \\
\text { Washington, DC } 20546-00\end{array}$ & $\begin{array}{l}\text { NAME(S) AND ADDRESS(ES) } \\
\text { Administration }\end{array}$ & $\begin{array}{l}\text { 10. SPONSORING/MONITORING } \\
\text { AGENCY REPORT NUMBER } \\
\text { NASA TM-2003-212115 } \\
\text { SAE-2002-01-1527 }\end{array}$ \\
\hline
\end{tabular}

Prepared for the General Aviation Technology Conference and Exhibition 2002 sponsored by the Society of Automotive Engineers, Wichita, Kansas, April 16-18, 2002. Billy P. Barnhart, Edward G. Dickes, and David R. Gingras, Bihrle Applied Research Inc., Jericho, New York 11753; Thomas P. Ratvasky, NASA Glenn Research Center. Responsible person, Thomas P. Ratvasky, organization code 5840, 216-433-3905.

\begin{tabular}{|l|l|}
\hline 12a. DISTRIBUTION/AVAILABILITY STATEMENT & 12b. DISTRIBUTION CODE
\end{tabular}

Unclassified - Unlimited

Subject Category: $05 \quad$ Distribution: Nonstandard

Available electronically at http://gltrs.grc.nasa.gov

This publication is available from the NASA Center for AeroSpace Information, 301-621-0390.

13. ABSTRACT (Maximum 200 words)

A high-fidelity simulation model for icing effects flight training was developed from wind tunnel data for the DeHavilland DHC-6 Twin Otter aircraft. First, a flight model of the un-iced airplane was developed and then modifications were generated to model the icing conditions. The models were validated against data records from the NASA Twin Otter Icing Research flight test program with only minimal refinements being required. The goals of this program were to demonstrate the effectiveness of such a simulator for training pilots to recognize and recover from icing situations and to establish a process for modeling icing effects to be used for future training devices.

\begin{tabular}{|c|c|c|c|}
\hline \multicolumn{3}{|l|}{ 14. SUBJECT TERMS } & $\begin{array}{c}\text { 15. NUMBER OF PAGES } \\
21\end{array}$ \\
\hline NSN 7540-01-280-5500 & & & $\begin{array}{l}\text { andard Form } 298 \text { (Rev. 2-89) } \\
\text { scribed by ANSI Std. Z39-18 }\end{array}$ \\
\hline
\end{tabular}



